\title{
Evaluation of Stress Transfer at Bone Implant Interface in Emulate Implant and Conventional Endosseous Implant: A Comparative 3-D Finite Element Analysis Study
}

\author{
S. Tyagi, K. Shetty, G. Issar, S, Rani, S. Kumar, H. G, Jagadeesh and S. Khan
}

\section{ABSTRACT} Aim: Aim of this study was to evaluate and compare stress transfer at bone
implant interface in customized root form implant and conventional
endosseous implant.

Materials and methodology: A three-dimensional finite element model of Emulate implant and conventional endosseous implant (nobel active $4.2 X 11.5 \mathrm{~mm}$ ) was generated. The implants were restored with metal ceramic crown and subjected to $20 \mathrm{Mpa}$ of axial applied stress. Resolved stresses were examined at four heights along the implant bone interface.

Results: In conventional endosseous implant with $100 \%$ osseointegration higher stresses (1.01-0.12 MPa) were concentrated on the facial surface of crest of implant. The stresses decreased from junction of cortical bone and trabecular bone to the apex of implant $(0.36-0.12 \mathrm{MPa})$. The maximum stresses on emulate implant with $100 \%$ osseointegration were at the facial surface of the crest of implant ( $0.05 \mathrm{MPa})$ which were comparatively lesser than conventional endosseous implant (1.01 MPa).

Conclusion: The degree of osseointegration affected the stress levels or distributions around both implants. Crestal stresses were always higher than apical stress. When the implants were $100 \%$ osseointegrated, then stresses were higher on conventional endosseous implant while in case of $50 \%$ osseointegration, stresses were higher on emulate implant.

Keywords: customized root form, endosseous, FEA, stress.
Published Online: October 30, 2020

ISSN: $2684-4443$

DOI :10.24018/ejdent.2020.1.5.29

S. Tyagi *

Post graduate trainee, I.T.S Dental

College, Muradnagar, India.

(e-mail: theshwetatyagi@gmail.com)

K. Shetty

Professor, I.T.S Dental College,

Muradnagar

G. Issar

Reader, I.T.S Dental College,

Muradnagar, India.

S. Rani

Reader, I.T.S Dental College,

Muradnagar, India.

S. Kumar

Professor, Teerthankar Dental College,

India.

H. G. Jagadeesh

HOD, Department of Prosthodontics,

I.T.S Dental College, Muradnagar, India.

S. Khan

Post graduate trainee, I.T.S Dental

College, Muradnagar, India.

*Corresponding Author

\section{INTRODUCTION}

The wellbeing and quality of life can depend on various factors, of which one can be a dentition with adequate function and esthetics. Dental Implants are becoming a common practice as tooth loss is also very common and patients prefer to find a fixed solution. High success rates and long term ( $>20$ years) follow up of patients treated with osseointegrated dental implants' have attracted the interest of dentists and dental researchers [1].

Subperiosteal form, blade form, ramus form, and endosseous form are some of the main types of dental implant designs that have been developed and used in clinical dentistry. Endosseous dental implants which serve to replace the tooth root are typically screw-shaped. Even though success rates are high, implant failures do occur. Excessive masticatory

loads have been blamed for implants failing for no other apparent reason. Crestal region has been reported to be area of initial breakdown of implant tissue interface in successfully osseointegrated implants.
The explanation offered for crestal bone loss is mainly based upon the stress distribution around the fixtures. It has been demonstrated by photoelastic and finite element analysis studies that stress is concentrated around the crestal region. A complex system of points (nodes) and elements is used in finite element analysis, which make a grid called as mesh. The material and structural properties such as Elastic modulous and poisson's ratio are contained in the programmed mesh, which define how the structure will react to certain loading conditions.

Nowadays commercial implants have cylindrical or tapered geometries with threads. But commercially standard dental implants provide only limited options for implant length, diameter, and thread parameters which sometimes cannot completely meet the requirements for all individual oral conditions.

Thus, customized dental implants tailored to individual patients' available quantity and quality of bone, not only preserve hard and soft tissues but also reduces rehabilitation time, opening a promising prospective for implant dentistry. Chen [2] in 2014 used modified root analogue zirconia implants fabricated by CAD/CAM technology for immediate 
tooth replacement, and excellent esthetic and functional results have been achieved with minimal bone resorption and soft tissue recession at a 2.5 year follow-up [2]. Also, studies have shown reduction in rate of bone resorption at crestal region following occlusal load. The objective of this study was to evaluate and compare stress transfer at bone implant interface in customized root form implant and conventional endosseous implant at two degrees of osseointegration.

\section{METHODOLOGY}

For this study a three-dimensional finite element model of Emulate implant (Fig. 1) and conventional endosseous implant (nobel active 4.2X11.5mm) was generated. (Fig. 2) The nobel active implant $(4.3 \times 11.5 \mathrm{~mm})$ was used as conventional endosseous implant. Nobel implant fixture and emulate implant fixture were scanned using WOL 3D scanner and were placed in mandibular second premolar jaw simulation. The superstructure of both Nobel active and emulate implant had the shape of mandibular second premolar simulating a metal-ceramic crown. Mesh was created for both the implants in jaw simulation (Fig. $3 \& 4$ ).

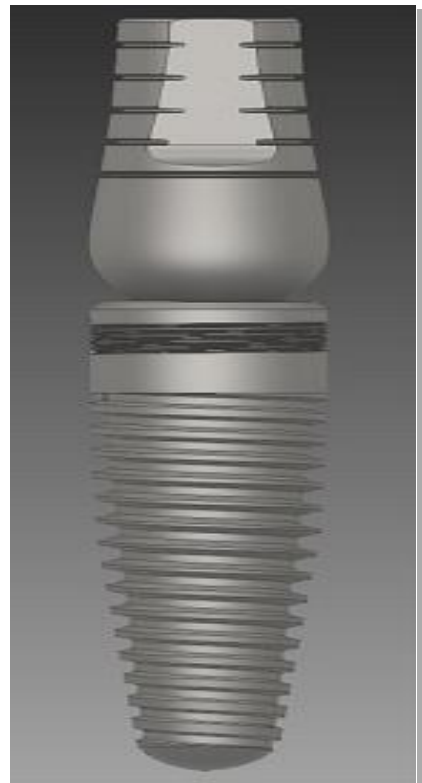

Fig. 1. Nobel Biocare Implant

FE Model

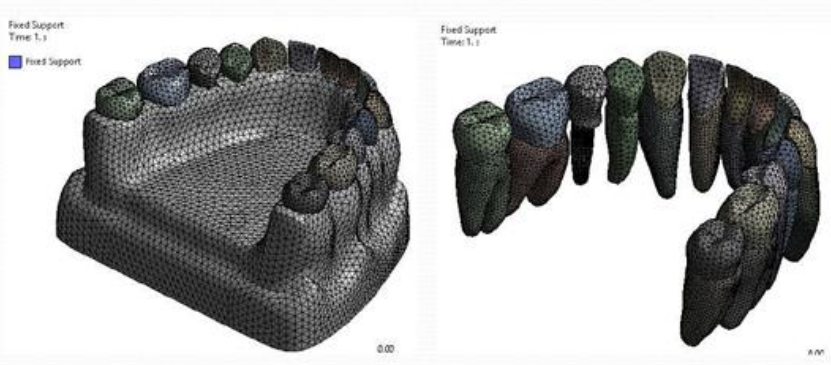

Fig. 3. Meshwork For Nobel (Conventional Implant).



Fig. 4. Meshwork for Emulate Implant.

In $50 \%$ osseointegration, the integrated and non-integrated areas were alternated along the implant fixtures. The local regions were randomly assigned as osseointegrated, but the overall model was $50 \%$ osseointegrated. The non-integrated areas were modeled as connective tissue or fibrous tissue of thickness $200-500$ microns, so that the associated elements were assigned extremely low mechanical properties but yet the connection was provided for local continuity of elements.

Stress analysis was done using structural stress analysis software, ANSYS. The stress analysis was carried out by applying loads at $50 \%$ and $100 \%$ osseointegration stages on emulate and conventional endosseous implant.

Points were chosen at heights corresponding to:

1. Zone 1: The crest of cortical bone.

2. Zone 2: The junction of cortical and trabecular bone.

3. Zone 3: Entirely the trabecular bone.

4. Zone 4: The Apex.

ANSYS generated simultaneous equation for each finite element through meshing and this was solved to yield predictable stress distribution around the emulate and conventional endosseous implant. In this study, both the implants were homogeneous, linear elastic and had isotropic mechanical properties. Based on past literature reports material properties for implant components were assigned.

\section{RESULTS}

The stress plots for the single replacement implant models with two different degrees of osseointegration were similar for each loading condition. For practical purposes they can be described together. Stress plots are color coded on the left side of the figures (Fig. 5 a, b, c, and d).

The results of this study showed that there are less stresses developed on emulate implant when there is $100 \%$ osseointegration but when there is only $50 \%$ oseeointegration the stresses are more on emulate implant.

This study focused only on the bone-implant interface even though the models demonstrated areas of high stress concentration within the fixture. In conventional endosseous implant with $100 \%$ osseointegration higher stresses (1.01$0.12 \mathrm{MPa}$ ) were concentrated on the facial surface of crest of implant. The resolved stresses decreased from junction of cortical bone and trabecular bone to the apex of implant $(0.36$ $-0.12 \mathrm{MPa})$.

For comparison, the stress values from the nodes for each level were averaged. Marked decrease in stress occurred 
from crest of the implant to the apex of implant. (0.8 Mpa). However, there were very few differences between the stresses on facial surface of trabecular bone in zone 3 and the apex of the implant. (0.0614 Mpa). The maximum stresses on emulate implant with $100 \%$ osseointegration were at the facial surface of the crest of implant $(0.05 \mathrm{MPa})$ which were comparatively lesser than conventional endosseous implant (1.01 MPa).

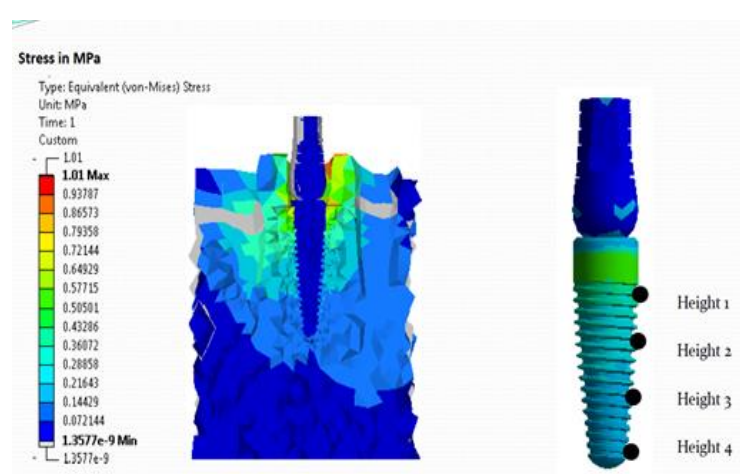

Fig. 5(a). Conventional Endosseous Implant (100\% Osseointegration).

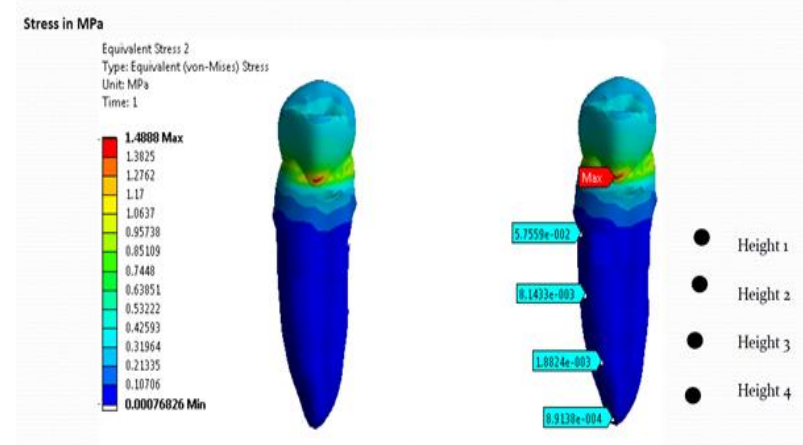

Fig. 5(b). Emulate Implant. (100\% Osseoinetgration).

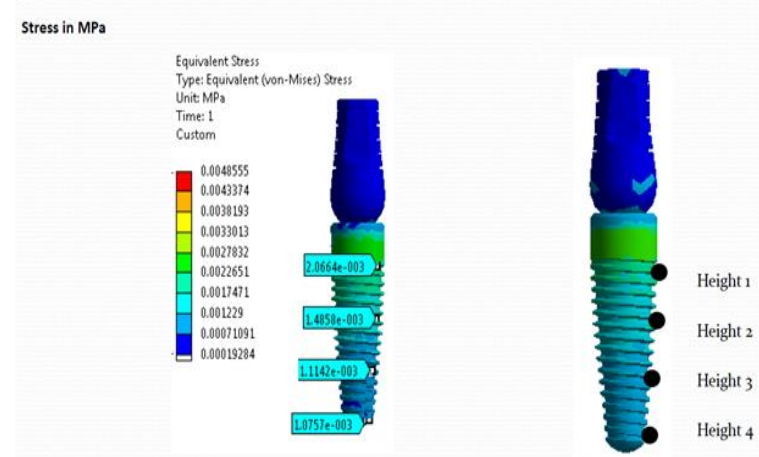

Fig. 5(c). Conventional Endosseous Implant. (50\% Osseoinetgration).
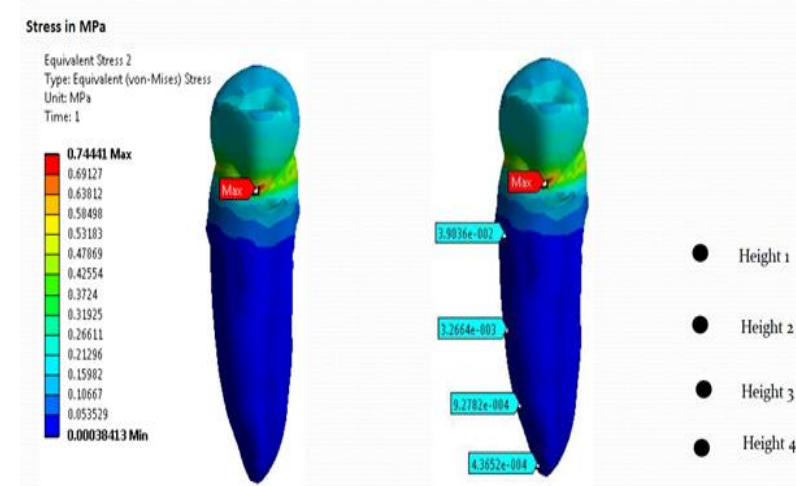

Fig. 5(d). Emulate Implant. (50\% Osseoinetgration).

\section{DISCUSSION}

Osseointegrated implants have been used successfully to restore function to fully and partially edentulous patients. Regardless of the high success rate of such dental implants, the literature reveals a significant incidence of technical failure, mainly related to excessive occlusal force [3], [4] and implant design [8].

The conventional endosseous implant design approximates the natural single-root shape and occupies most of the alveolus space after insertion. It exhibits a natural profile and keeps the long axis of the natural tooth, which reduces the undesired lateral force [4], [5]. The literature indicates that a better initial stability can be obtained with conventional endosseous implant. Furthermore, in agreement with previous studies, [6], [7] adding threads also transferred and dispersed the occlusal force effectively and more evenly to the surrounding bone tissue, as shown in the finite element analysis (FEA) results.

Block et al found that the implants had less than half of the intraosseous interface in direct contact with bone for loaded implants in dogs, while Barth et al. [15] reported integration levels approximating $80 \%$.

The significance of the percentage of osseointegration has not yet been fully investigated. A reason for that is the difficulty to assess this percentage clinically. Finite Element Analysis (FEA) make possible the simulation of clinical situations involving dental implants with different percentages and patterns of osseointegration.

The present study evaluated and compared the interfacial stresses between customised or emulate implant and conventional endosseous implant through finite element analysis.

In this study, two implant models were selected, one threaded conventional endosseous implant and the other customised root form implant or emulate implant.

Both these implants were placed in mandibular second premolar jaw simulation with $100 \%$ and $50 \%$ osseointegration. In $50 \%$ osseointegration, the integrated and non-integrated areas were alternated along the implant fixtures. The local regions were randomly assigned as osseointegrated, but the overall model was $50 \%$ osseointegrated. The non-integrated areas were modeled as connective tissue or fibrous tissue of thickness $200-500$ microns, so that the associated elements were assigned extremely low mechanical properties but yet the connection was provided for local continuity of elements.

From many clinical studies on the behaviour of implants during mastication, it can be concluded that stress on implant supported prostheses is comparable and possibly a little lower than that for natural teeth [10], [11]. It covers a wide range of values which is from 10 to $50 \mathrm{~N}$ for normal masticatory function [12], [13]. Hence, in this study a load of $20 \mathrm{~N}$ was applied to both the models.

The results of this study showed that there are less stresses developed on emulate implant when there is $100 \%$ osseointegration but when there is only $50 \%$ oseeointegration the stresses are more on emulate implant.

In conventional endosseous implant with $100 \%$ osseointegration higher stresses (1.01-0.12 $\mathrm{MPa}$ ) were concentrated on the facial surface of crest of implant. This is 
in agreement with studies by Hoshaw et a1. [14] who conducted 3D-FEA and animal studies of tibial bone under cyclic stresses. The resolved stresses decreased from junction of cortical bone and trabecular bone to the apex of implant (0.36-0.12 MPa).

For comparison, the stress values from the nodes for each level were averaged. Marked decrease in stress occurred from crest of the implant to the apex of implant.(0.8 Mpa) However, there were very few differences between the stresses on facial surface of trabecular bone in zone 3 and the apex of the implant (0.0614 Mpa).

The maximum stresses on emulate implant with $100 \%$ osseointegration were at the facial surface of the crest of implant (0.05 $\mathrm{MPa})$ which were comparatively lesser than conventional endosseous implant (1.01 MPa).

So, the pattern of results with $50 \%$ osseointegration of emulate implant and conventional osseointegrated implant varied. There were more stresses on emulate implant (0.039$0.0004 \mathrm{MPa})$ as compared to conventional osseointegrated implant (0.002-0.001MPa).

Table I, II, III, and IV shows Von Mises Stress averages for different interfacial levels of emulate and conventional endosseous implants with $100 \%$ and $50 \%$ osseointegration.

It has been shown that clinically successful implants have less than half of the intraosseous interface in direct contact with bone [9], [10]. So, this study proves this context that conventional endosseous implants are better when there is only $50 \%$ osseointegration. Therefore, null hypothesis is rejected.

TABLE I: RESULTS OF CONVENTIONAL ENDOSSEOUS IMPLANT (100\% OSSEOINTEGRATION)

\begin{tabular}{ccc}
\hline Load Case & Height & $\begin{array}{c}\text { Max Stress in N/mm } \\
(\mathrm{MPa})\end{array}$ \\
\hline 1 & 1.01 \\
2 & 0.36411 \\
3 & 0.1853 \\
4 & 0.12391 \\
\hline
\end{tabular}

TABLE II: RESULTS OF EMULATE IMPLANT (100\% OSSEOINTEGRATION)

\begin{tabular}{ccc}
\multicolumn{3}{c}{$(100 \%$ OSSEOINTEGRATION $)$} \\
\hline \multirow{2}{*}{ Load Case } & Height & $\begin{array}{c}\text { Max Stress in N/mm } \\
(\mathrm{MPa})\end{array}$ \\
\hline 1 & 0.0576 \\
2 & 0.0081 \\
3 & 0.0019 \\
4 & 0.0009 \\
\hline
\end{tabular}

TABLE III: RESULTS OF CONVENTIONAL ENDOSSEOUS IMPLANT (50\% OSSEOINTEGRATION)

\begin{tabular}{ccc}
\hline Load Case & Height & $\begin{array}{c}\text { Max Stress in N/mm } \\
(\mathrm{MPa})\end{array}$ \\
\hline 1 & 0.002006 \\
2 & 0.001486 \\
3 & 0.001114 \\
4 & 0.001076 \\
\hline
\end{tabular}

TABLE IV: RESULTS OF EMULATE IMPLANT (50\% OSSEOINTEGRATION)

\begin{tabular}{ccc}
\multicolumn{3}{c}{$(50 \%$ OsseointegRATION) } \\
\hline \multirow{2}{*}{ Load Case } & Height & $\begin{array}{c}\text { Max Stress in N/mm } \\
(\mathrm{MPa})\end{array}$ \\
\hline 1 & 0.039 \\
2 & 0.0033 \\
3 & 0.0009 \\
4 & 0.0004 \\
\hline
\end{tabular}

\section{CONCLUSION}

1. The degree of osseointegration affected the stress levels or distributions.

2. Crestal stresses were always higher than apical stress.

3 . When the implants were $100 \%$ osseointegrated, then stresses were on conventional endosseous implant.

4. In case of $50 \%$ osseointegration, stresses were higher on emulate implant.

\section{REFERENCES}

[1] Gaviria L, Saleido J, Guda T. current trends in dental implants. J Korean Assoc Oral Maxillofac Surg 2014:40:2-50.

[2] Chen et al. Design and manufacture of customized dental implants using reverse engineering and selective laser melting technology. $J$ Pros Dent 2014:112(5):1089-1095.

[3] Jemt T, Lekholm U, Adell R. Osseointegrated implants in the treatment of partially edentulous patients: a preliminary study on 876 consecutively placed fixtures. Int J Oral Maxillofac Implants. 1989; 4:211-217.

[4] Sagara M, Akagawa Y, Nikai H, et al. The effects of early occlusal loading on one-stage titanium alloy implants in beagle dogs: a pilot study. J Prosthet Dent. 1993; 69:281-288.

[5] Pirker W, Kocher A. Immediate, nonsubmerged, root-analogue zirconia implant in single tooth replacement. Int J Oral Maxillofac Surg 2008; 37:293-5.

[6] de Cos Juez FJ, Sánchez Lasheras F, Garcí Nieto PJ, Álvarez-Arenal A. Non-linear numerical analysis of a double-threaded titanium alloy dental implant by FEM. Applied Mathematics and Computation 2008;206:952-67.

[7] Chang JZ, Chen YJ, Tung YY, Chiang YY, Lai EH, Chen WP, et al. Effects of thread depth, taper shape, and taper length on the mechanical properties of mini-implants. Am J Orthod Dentofacial Orthop 2012;141: 279-88.

[8] Siegele D, Soltesz U. Numerical investigations of the influence of implant shape on stress distribution in the jaw bone. Int J Oral Maxillofac Implants. 1989;4:333-340.

[9] Roberts, W. E., Bone tissue interface. J Den Edu, 1988;52: 804-809.

[10] Block, M. S., Finger, I. M., Fontenot, M. G. and Kent, J. N., Loaded hydroxylapatite-coated and grit-blasted titanium implants in dogs. Int J Oral Maxillofac Implants, 1989;4:219-225.

[11] Lundgren, D., Laurell, L., Falk, H. and Bergendal, T., Occlusal force pattern during mastication in dentition with mandibular fixed partial dentures supported on osseointegrated implants. J Pros Dent, 1987;58:197-203.

[12] Falk, H., Laurell, L. and Lundgren, D., Occlusal force pattern in dentitions with mandibular implant-supported fixed cantilever prostheses occluded with complete dentures. Int J Oral Maxillofac Implants. 1989; 4: 55-62.

[13] Anderson, D. J., Measurement of stress in mastication. J of Dent Research, 1956;35: 664-670.

[14] Hoshaw, S. J., Brunski, J. B. and Cochran, G. V. B., Mechanical loading of Branemark implants affects interfacial bone modeling and remodeling. Int J Oral Maxillofac Implants, 1994; 9:345-359.

[15] Barth, E., Johansson, C. and Albrektsson, T., Histologic comparison of ceramic and titanium implants in cats. Int J Oral Maxillofac Implants.1990; 5,227-23. 